\title{
Deep vein thrombosis: a clinical review
}

This article was published in the following Dove Press journal:

Journal of Blood Medicine

26 April 20II

Number of times this article has been viewed

\section{Emeka Kesieme' \\ Chinenye Kesieme ${ }^{2}$ \\ Nze Jebbin ${ }^{3}$ \\ Eshiobo Irekpita' \\ Andrew Dongo'}

'Department of Surgery, Irrua Specialist Teaching Hospital, Irrua, Nigeria; ${ }^{2}$ Department of Paediatrics, Irrua Specialist Teaching Hospital, Irrua, Nigeria; ${ }^{3}$ Department of Surgery, University of Port Harcourt Teaching Hospital, Port-Harcourt, Nigeria
Correspondence: Emeka Kesieme Department of Surgery, Irrua Specialist Teaching Hospital, Irrua, PMB 8, Irrua, Edo State, Nigeria

Tel +234808088I312

Email ekesieme@gmail.com
Background: Deep vein thrombosis (DVT) is the formation of blood clots (thrombi) in the deep veins. It commonly affects the deep leg veins (such as the calf veins, femoral vein, or popliteal vein) or the deep veins of the pelvis. It is a potentially dangerous condition that can lead to preventable morbidity and mortality.

Aim: To present an update on the causes and management of DVT.

Methods: A review of publications obtained from Medline search, medical libraries, and Google.

Results: DVT affects $0.1 \%$ of persons per year. It is predominantly a disease of the elderly and has a slight male preponderance. The approach to making a diagnosis currently involves an algorithm combining pretest probability, D-dimer testing, and compression ultrasonography. This will guide further investigations if necessary. Prophylaxis is both mechanical and pharmacological. The goals of treatment are to prevent extension of thrombi, pulmonary embolism, recurrence of thrombi, and the development of complications such as pulmonary hypertension and postthrombotic syndrome.

Conclusion: DVT is a potentially dangerous condition with a myriad of risk factors. Prophylaxis is very important and can be mechanical and pharmacological. The mainstay of treatment is anticoagulant therapy. Low-molecular-weight heparin, unfractionated heparin, and vitamin $\mathrm{K}$ antagonists have been the treatment of choice. Currently anticoagulants specifically targeting components of the common pathway have been recommended for prophylaxis. These include fondaparinux, a selective indirect factor Xa inhibitor and the new oral selective direct thrombin inhibitors (dabigatran) and selective factor Xa inhibitors (rivaroxaban and apixaban). Others are currently undergoing trials. Thrombolytics and vena caval filters are very rarely indicated in special circumstances.

Keywords: deep vein thrombosis, pulmonary embolism, venous thromboembolism, prophylaxis, treatment

\section{Introduction}

The term thrombosis refers to the formation, from constituents of blood, of an abnormal mass within the vascular system of a living animal. When this process occurs within the deep veins, it is referred to as deep vein thrombosis (DVT).

An accurate diagnosis of DVT is extremely important to prevent potentially fatal acute complication of pulmonary embolism (PE) and long-term complications of postphlebitis syndrome and pulmonary hypertension. It is also important to avoid unjustified therapy with anticoagulants with associated high risk of bleeding in patients misdiagnosed with the condition. ${ }^{1}$ 
Clinical features are nonspecific; hence new strategies for diagnosing this condition have evolved.

We aim to critically review the current state of knowledge on this subject, with a view to updating clinicians on the prophylaxis and treatment of DVT.

\section{Methods}

A literature review of DVT was done from 1970 to date using a manual library search, journal publications on the subject, and Medline. Full texts of the materials, including those of relevant references were collected and studied. Information relating to the epidemiology, pathology, clinical presentation, investigations, prophylaxis, treatment, and complications was extracted from the materials.

\section{Results}

\section{Epidemiology}

DVT is a major and a common preventable cause of death worldwide. It affects approximately $0.1 \%$ of persons per year. The overall average age- and sex-adjusted annual incidence of venous thromboembolism (VTE) is 117 per 100,000 (DVT, 48 per 100,000; PE, 69 per 100,000), with higher age-adjusted rates among males than females (130 vs 110 per 100,000 , respectively). ${ }^{2}$ Both sexes are equally afflicted by a first VTE, men having a higher risk of recurrent thrombosis. ${ }^{3,4}$ DVT is predominantly a disease of the elderly with an incidence that rises markedly with age. ${ }^{2}$

A study by Keenan and White revealed that AfricanAmerican patients are the highest risk group for first-time VTE. Hispanic patients' risk is about half that of Caucasians. The risk of recurrence in Caucasians is lower than that of African-Americans and Hispanics. ${ }^{5}$

The incidence of VTE is low in children. Annual incidences of 0.07 to 0.14 per 10,000 children and 5.3 per 10,000 hospital admissions have been reported in Caucasian studies. ${ }^{6,7}$ This low incidence may be due to decreased capacity to generate thrombin, increased capacity of alpha-2-macroglobulin to inhibit thrombin, and enhanced antithrombin potential of vessel walls. The highest incidence in childhood is during the neonatal period, followed by another peak in adolescence. ${ }^{8}$ The incidence rate is comparatively higher in adolescent females because of pregnancy and use of oral contraceptive agents. ${ }^{9}$

Pregnant women have a much higher risk of VTE than nonpregnant women of similar age and the risk has been shown to be higher after cesarian section than after vaginal delivery. ${ }^{10}$ In a study conducted in an African population, the documented rate was 48 DVT per 100,000 births per year. ${ }^{11}$
The incidence appears to be highest in the postpartum period. ${ }^{11,12}$

The approximate risk for DVT following general surgery procedures is $15 \%$ to $40 \%$. It nearly doubles after hip or knee replacement surgery or hip fracture surgery $(40 \%$ to $60 \%) .{ }^{13}$ Geerts et al revealed that without prophylaxis, fatal PE occurs in $0.2 \%$ to $0.9 \%$ of patients undergoing elective general surgery, $0.1 \%$ to $2 \%$ of those undergoing elective hip replacement and up to $2.5 \%$ to $7.5 \%$ of those undergoing surgery for hip fracture. ${ }^{14}$ Though regarded mainly as a surgical complication, most symptomatic VTE events and fatal PE occur in medical patients. ${ }^{15}$

\section{Pathogenesis/classification}

Thrombus formation preferentially starts in the valve pockets of the veins of the calf and extends proximally. This is especially true for those that occur following surgery. ${ }^{16}$ Though most thrombi begin intraoperatively, some start a few days, weeks, or months after surgery. Lending its support to the origin of thrombus in valve pockets is a recent hypothesis of an increased expression of endothelial protein $\mathrm{C}$ receptor (EPCR) and thrombomodulin (TM) and a decreased expression of Von Willebrand factor (vWF) noted in valve sinus endothelium compared with vein luminal endothelium. This means an upregulation of anticoagulants (EPCR, TM) and a downregulation of procoagulant (vWF) properties of the valvular sinus endothelium. ${ }^{17}$

Thrombus is composed predominantly of fibrin and red cells (red or static thrombus). Venous thrombus must be differentiated from postmortem clot at autopsy. Postmortem clots are gelatinous and have a dark red dependent portion (formed by red cells that have settled by gravity and a yellow chicken fat supernatant resembling melted and clotted chicken fat). They are usually not attached to the underlying wall. This is in contrast to the venous thrombi which are firmer. They almost always have a point of attachment to the wall and transection reveals vague strands of pale gray fibrin. ${ }^{18}$

DVT in the lower limb can be classified as a) proximal, when the popliteal vein or thigh veins are involved or b) distal, when the calf veins are involved. Clinically, proximal vein thrombosis is of greater importance and is associated with serious chronic diseases such as active cancer, congestive cardiac failure, respiratory insufficiency, or age above 75 years, whereas distal thrombosis is more often associated with risk factors such as recent surgery and immobilization. Fatal PE is far more likely to result from proximal DVT. ${ }^{19}$ Post-thrombotic syndrome, a chronic, potentially disabling 
condition characterized by leg swelling, pain, venous ectasia, and skin induration, is established by 1 year after DVT in $17 \%$ to $50 \%$ of cases. $^{20}$

Uncommon presentations of VTE are forms of acute massive venous thrombosis with obstruction of venous drainage to the extremity. These include phlegmasia alba dolens, phlegmasia cerulea dolens, and venous gangrene. In phlegmasia alba dolens, the thrombosis involves only the major deep venous channels of the extremity, sparing collateral veins. However, in phlegmasia cerulea dolens, the thrombosis extends to the collateral vein, resulting in massive fluid sequestration and more significant edema.

\section{Clinical features}

History and clinical examination are not reliable ways of diagnosing DVT. ${ }^{21}$ Lower extremity DVT can be symptomatic or asymptomatic. Patients with lower extremity DVT often do not present with erythema, pain, warmth, swelling, or tenderness. Symptomatic patients with proximal DVT may present with lower extremity pain, calf tenderness, and lower extremity swelling. ${ }^{22,23}$ Homans' sign may be demonstrable in DVT. Most of these features lack specificity; hence clinical evaluation usually implies the need for further evaluation. The left leg is the commonest site for venous thrombosis in pregnancy ${ }^{11}$ and in acute massive venous thrombosis. This may be due to compression of the left iliac vein by the right iliac artery (May-Thurner syndrome). ${ }^{24}$

Phlegmasia alba dolens is characterized by edema, pain, and blanching without cyanosis while phlegmasia cerulea dolens is characterized by these features in addition to cyanosis, which characteristically progresses from distal to proximal areas and bleb/bulla formation.

\section{Risk factors}

Rudolph Virchow described three conditions that predispose to thrombus, the so-called Virchow's triad. This triad includes endothelial injury, stasis or turbulence of blood flow, and blood hypercoagulability.

Stasis and endothelial injury are important in DVT following trauma or surgery while hypercoagulability is responsible for most cases of spontaneous DVT. At least $96 \%$ of patients treated for VTE have been shown to have at least one risk factor. ${ }^{25}$

Risk can be classified as acquired or genetic. When genetic defects are combined with one or more acquired risk factors, or in combined genetic defects or combination of two acquired defects, it results in a risk of VTE that exceeds the separate effects of a single factor. ${ }^{26}$
In adults, the clinical conditions that predispose to VTE are increasing age, cancer and its treatment, prolonged immobility, stroke or paralysis, previous VTE, congestive heart failure, acute infection, pregnancy or puerperium, dehydration, hormonal treatment, varicose veins, long air travel, acute inflammatory bowel disease, rheumatological disease, and nephrotic syndrome. Other acquired factors that have recently been associated with increased risk of VTE disorders include persistent elevation of D-dimer and atherosclerotic disease. ${ }^{27}$

Oral contraceptive pills, especially those that contain third-generation progestins increase the risk of VTE ${ }^{28}$ Risk of DVT associated with long-duration air travel is called economy class syndrome. ${ }^{29}$ It is $3 \%$ to $12 \%$ in a long-haul flight with stasis, hypoxia, and dehydration being pathophysiological changes that increase the risk. ${ }^{30}$ van Aken et al demonstrated that subjects with elevated levels of interleukin- 8 have increased risk of venous thrombosis, supporting an important role of inflammation in etiopathogenesis of venous thrombosis. $^{31}$

Clayton et al have described a strong association between recent respiratory infection and VTE. They demonstrated an increased risk of DVT in the month following infection and $\mathrm{PE}$ in 3 months following infection, both persisting up to a year. ${ }^{32}$

In the pediatric age group, the most important triggering risk factors for development of thromboembolism are the presence of central venous lines, cancer, and chemotherapy. Severe infection, sickle cell disease, trauma, and antiphospholipid syndromes are clinical conditions associated with hypercoagulability states. ${ }^{33}$

Genetic risk factors can be divided into strong, moderate, and weak factors. ${ }^{34}$ Strong factors are deficiencies of antithrombin, protein $\mathrm{C}$ and protein $\mathrm{S}$. Moderately strong factors include factor V Leiden, prothrombin 20210A, non-O blood group, and fibrinogen 10034T. Weak genetic risk factors include fibrinogen, factor XIII and factor XI variants.

\section{Clinical prediction rules}

A commonly accepted evidence-based approach to diagnosis of VTE is the use of a clinical model that standardizes the clinical assessment (combining risk factors, signs and symptoms) and subsequently stratifies patients suspected of DVT.

Though this model has been used for both primary care patients and secondary settings, there is no doubt that it does not guarantee accurate estimation of risk in primary care patients in whom DVT is suspected. ${ }^{35}$ 
The most commonly recommended model is that developed by Wells and colleagues. Based on clinical presentation and risk factors, an initial model was developed to group patients into low-, moderate-, and high-probability groups. The high-probability group has an $85 \%$ risk of DVT, the moderate-probability group a $33 \%$ risk, and the low-probability group a $5 \%$ risk. ${ }^{36}$ However, in a later study, Wells and colleagues further streamlined the diagnostic process by stratifying patients into two risk categories: "DVT unlikely" if the clinical score is $\leq 1$ and "DVT likely" if the clinical score is $>1$ (Table 1$){ }^{37}$

\section{D-dimer assay}

D-dimer is a degradation product of cross-linked fibrin that is formed immediately after thrombin-generated fibrin clots are degraded by plasmin. It reflects a global activation of blood coagulation and fibrinolysis. ${ }^{38}$ It is the best recognized biomarker for the initial assessment of suspected VTE. The combination of clinical risk stratification and a D-dimer test can exclude VTE in more than $25 \%$ of patients presenting with symptoms suggestive of VTE without the need for additional investigations. ${ }^{39}$ Even in patients with clinically suspected recurrent DVT, this combination (clinical evaluation and D-dimer) has proved to be useful for excluding DVT, especially in patients included in the lower clinical pretest probability group..$^{40}$

Levels of D-dimer can be popularly measured using three types of assay:

- Enzyme linked immunosorbent assay (ELISA).

- Latex agglutination assay.

- Red blood cell whole blood agglutination assay (simpliRED).

These assays differ in sensitivity, specificity, likelihood ratio, and variability among patients with suspected VTE. ELISAs dominate the comparative ranking among D-dimer assays for sensitivity and negative likelihood ratio.

D-dimer assays are highly sensitive (values up to 95\%), but have poor specificity to prove VTE. The negative predictive value for patients with a negative D-dimer blood test is nearly $100 \%$. Hence a negative value of D-dimer may safely rule out both DVT and PE. False positive D-dimer results have been noted in inflammation, ${ }^{41}$ pregnancy, ${ }^{42}$ malignancy, ${ }^{43}$ and the elderly. ${ }^{44}$ Clinical usefulness of the measurement of D-dimer has been shown to decrease with age..$^{45}$ The use of age-dependent cut-off values of D-dimer assays is still a matter of controversy. Several studies have shown that the levels of D-dimer assays increase with gestational age and in complicated pregnancies as observed in preterm labor, abruptio placenta, and gestational hypertension. ${ }^{46-48}$ Elevated D-dimer was found to be predictive of poor outcome (persistent thrombosis, recurrence or post-thrombotic syndrome) in children with an acute thrombotic event. ${ }^{49}$ False negative D-dimer results have been noted after heparin use; hence it has been recommended that D-dimer assay should be done prior to administering heparin to a patient. ${ }^{43}$ Other causes of false negative D-dimer results are late presentation (symptoms longer than 2 weeks) and small below-knee DVT.

\section{Venous ultrasonography}

Venous ultrasonography is the investigation of choice in patients stratified as DVT likely. ${ }^{50}$ It is noninvasive, safe, available, and relatively inexpensive. There are three types of venous ultrasonography: compression ultrasound (B-mode imaging only), duplex ultrasound (B-mode imaging and Doppler waveform analysis), and color Doppler imaging alone. In duplex ultrasonography, blood flow in normal vein is spontaneous, phasic with respiration, and can be augmented by manual pressure. In color flow sonography, pulsed Doppler signal is used to produce images..$^{51}$ Compression ultrasound is typically performed on the proximal deep veins, specifically the common femoral, femoral, and popliteal veins, whereas a combination of duplex ultrasound and color duplex is more often used to investigate the calf and iliac veins. ${ }^{52}$

The major ultrasonographic criterion for detecting venous thrombosis is failure to compress the vein lumen under gentle probe pressure. Other criteria for ultrasonographic diagnosis of venous thrombosis include loss of phasic pattern in which flow is defined as continuous, response to valsava or augmentation (Duplex ultrasound), and complete absence of spectral or color Doppler signals from the vein lumen..$^{53}$

The other advantages of venous ultrasound are its ability to diagnose other pathologies (Baker's cysts, superficial or intramuscular hematomas, lymphadenopathy, femoral aneurysm, superficial thrombophlebitis, and abscess), and the fact that there is no risk of exposure to irradiation, while its major limitation is its reduced ability to diagnose distal thrombus. ${ }^{22}$ Venous compressibility may be limited by a patient's characteristics such as obesity, edema, and tenderness as well as by casts or immobilization devices that limit access to the extremity. Compression B-mode ultrasonography with or without color Duplex imaging has a sensitivity of $95 \%$ and a specificity of $96 \%$ for diagnosing symptomatic, proximal DVT. ${ }^{54}$ For DVT in the calf vein, the sensitivity of venous ultrasound is only $73 \%{ }^{55}$

Repeat or serial venous ultrasound examination is indicated for initial negative examination in symptomatic patients who are highly suspicious for DVT and in whom 
an alternative form of imaging is contraindicated or not available. Serial testing has been found unnecessary for those in whom DVT is unlikely by Wells score and has a negative D-dimer test.

\section{Contrast venography}

Venography is the definitive diagnostic test for DVT, but it is rarely done because the noninvasive tests (D-dimer and venous ultrasound) are more appropriate and accurate to perform in acute DVT episodes. It involves cannulation of a pedal vein with injection of a contrast medium, usually noniodinated, eg, Omnipaque. A large volume of Omnipaque diluted with normal saline results in better deep venous filling and improved image quality. ${ }^{56}$

The most reliable cardinal sign for the diagnosis of phlebothrombosis using venogram is a constant intraluminal filling defect evident in two or more views. ${ }^{56}$ Another reliable criterion is an abrupt cutoff of a deep vein, a sign difficult to interpret in patients with previous DVT. ${ }^{57}$ It is highly sensitive especially in identifying the location, extent and attachment of a clot and also highly specific.

Being invasive and painful remains its major setback. The patient is exposed to irradiation and there is also an additional risk of allergic reaction and renal dysfunction. Occasionally a new DVT may be induced by venography, ${ }^{58}$ probably due to venous wall irritation and endothelial damage. The use of nonionic contrast medium has reduced considerably risks of anaphylactic reaction and thrombogenecity or may have even eliminated them. ${ }^{59,60}$

\section{Impedance plethysmography}

The technique is based on measurement of the rate of change in impedance between two electrodes on the calf when a venous occlusion cuff is deflated. Free outflow of venous blood produces a rapid change in impedance while delay in outflow, in the presence of a DVT, leads to a more gradual change. ${ }^{61}$ It is portable, safe, and noninvasive but its main drawback remains an apparent insensitivity to calf thrombi and small, nonobstructing proximal vein thrombi.

\section{Magnetic resonance imaging (MRI)}

This investigative modality has high sensitivity in detecting calf and pelvic DVTs, ${ }^{62}$ and upper extremity venous thromboses. ${ }^{63}$ It is also relevant in ruling out differential diagnoses in patients suspected of DVT. MRI is the diagnostic test of choice for suspected iliac vein or inferior vena caval thrombosis when computed tomography venography is contraindicated or technically inadequate. There is no risk of ionizing radiation but it is costly, scarce, and reader expertise is required.

\section{Algorithm for the diagnosis of DVT}

The first step is the pretest probability assessment using an established model such as the Wells score (Figure 1). If score is $\leq 1$ (DVT unlikely), D-dimer assay is done. If assay is negative, DVT is excluded and the patient can be discharged without further investigations. If assay is positive, a venous ultrasound is indicated. Negative venous ultrasound scan excludes the diagnosis of DVT. Diagnosis of DVT is made if venous ultrasonography is positive.

If the DVT is likely (probability score $\geq 2$ ), venous ultrasonography is indicated. DVT is diagnosed and treated if venous ultrasound is positive. If negative, D-dimer assay should be done. Negative D-dimer excludes the diagnosis of DVT while a positive result is an indication for follow-up studies; repeat ultrasound in 6 to 8 days or do venography. This algorithm is not used in pregnancy because D-dimer is falsely elevated.

\section{Prophylaxis \\ Mechanical}

Mechanical methods of prophylaxis against DVT include intermittent pneumatic compression (IPC) device, graduated compression stocking (GCS), and the venous foot pump. Intermittent pneumatic compression enhances blood flow in the deep veins of the leg, preventing venous stasis and hence preventing venous thrombosis. ${ }^{64}$ Agu et al have shown that these mechanical methods reduce postoperative venous thrombosis. ${ }^{65}$ A Cochrane review showed a reduction of

Table I Pretest probability assessment (Wells score)

\begin{tabular}{ll}
\hline & Points \\
\hline Active cancer (treatment ongoing or within previous & I \\
6 months or palliative) & I \\
Paralysis, paresis, or recent plaster immobilization of the & I \\
lower extremities & \\
Recently bedridden for 3 days or major surgery within & I \\
I 2 weeks requiring general or regional anesthesia & I \\
Localized tenderness along the distribution of the deep & I \\
veins & Entire leg swollen \\
Calf swelling 3 cm $>$ asymptomatic side (measured I0 cm \\
below tibial tuberosity) \\
Pitting edema limited to the symptomatic leg \\
Collateral superficial veins (nonvaricose) \\
Previous DVT \\
Alternative diagnosis as likely as or more likely than DVT
\end{tabular}

Notes: DVT unlikely: $\leq$ I; DVT likely: $\geq 2$ 
Table 2 Advantages of low-molecular-weight heparin over unfractionated heparin

- Greater bioavailability

- Predictability and dose-dependent plasma level

- Less risk of bleeding

- Lower incidence of heparin-induced thrombocytopenia

- Lower risk of heparin-induced osteoporosis

- No need for laboratory monitoring

- Can be safely administered in outpatient

- Duration of anticoagulant effect is longer, permitting once- or twice-daily administration

VTE by about $50 \%$ with the use of graduated compression stockings. ${ }^{66}$ Intermittent pneumatic compression, in addition to preventing venous thrombosis, has been shown to reduce plasminogen activator inhibitor-1, thereby increasing endogenous fibrinolytic activity. ${ }^{67}$

Compared with compression alone, combined prophylactic modalities decrease significantly the incidence of VTE. Compared with pharmacological prophylaxis alone, combined modalities reduce significantly the incidence of DVT, but the effect on PE is unknown. This is recommended especially for high-risk patients. ${ }^{6}$

A mechanical method of DVT prophylaxis is indicated in patients at high risk of bleeding with anticoagulation prophylaxis. These includes patients with active or recent gastrointestinal bleeding, patients with hemorrhagic stroke, and those with hemostatic defects such as severe thrombocytopenia. ${ }^{69}$ It is contraindicated in patients with evidence of leg ischemia due to peripheral vascular disease. There is a theoretical risk of fibrinolysis and clot dislodgement. ${ }^{70}$ Leg wrappings and stockings with no pressure gradient are ineffective in the prevention of DVT. ${ }^{71}$ Hilleren-Listerud demonstrated that knee-length GCS and IPC devices are as effective as thigh-length GCS and IPC devices. They are also more comfortable, cheaper and more user-friendly for the patient. ${ }^{72}$

Chin et al compared the efficacy and safety of different modes of thromboembolic prophylaxis (IPC, GCS, and enoxaparin) for elective total knee arthroplasty (TKA) in Asian patient and recommended IPC as the preferred method of thromboprophylaxis for TKA. ${ }^{73}$ However no meaningful difference in performance between GCS and IPC was demonstrated by Morris and Woodcock. ${ }^{74}$

Daily use of elastic compression stockings after proximal DVT reduced the incidence of postphlebitis syndrome by $50 \% .^{20}$

Other mechanical means in both medical and surgical patients include ambulation and exercises involving foot extension. They improve venous flow and should be encouraged.

\section{Pharmacological}

Unfractionated heparin (UFH), low-molecular-weight heparins (LMWH), fondaparinux, and the new oral direct selective thrombin inhibitors and factor $\mathrm{Xa}$ inhibitors are

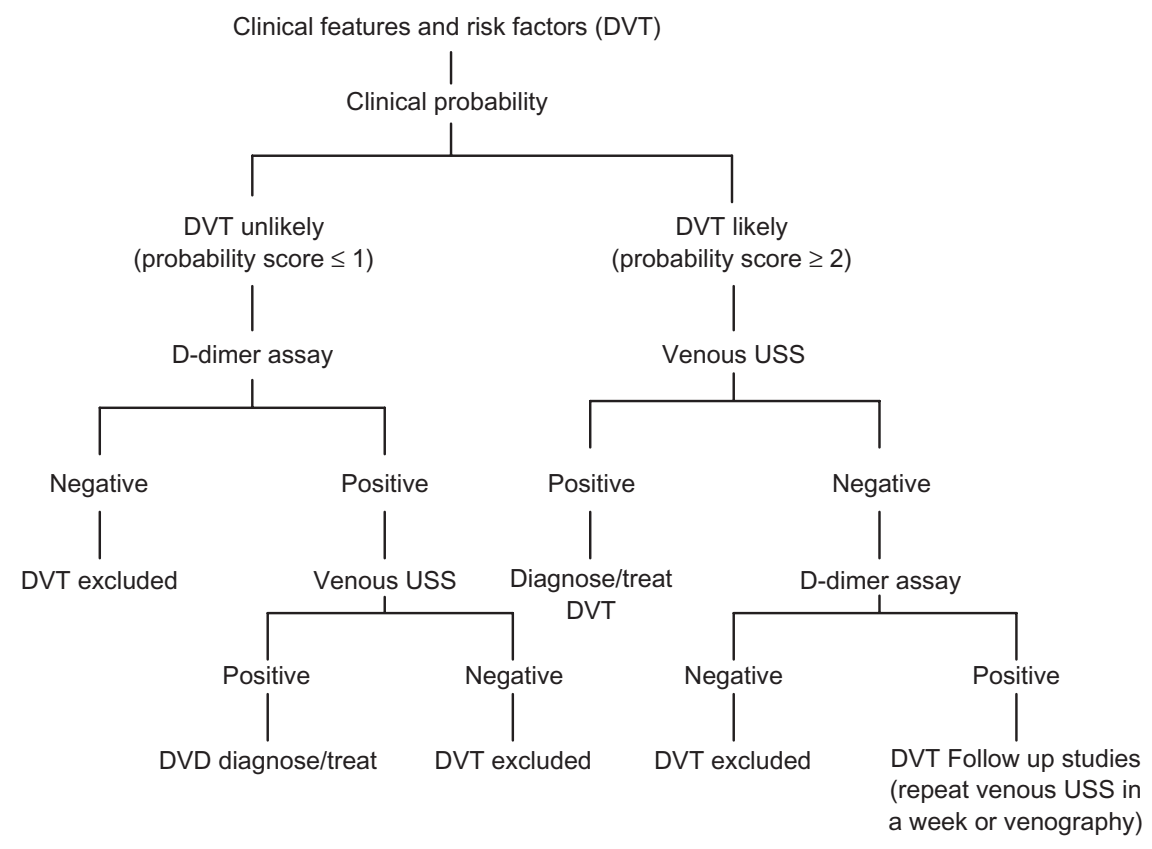

Figure I Algorithm for diagnosing DVT using clinical assessment, D-dimer testing, and venous ultrasonography. Abbreviation: USS, ultrasound. 
effective pharmacological agents for prophylaxis of DVT. Studies have shown that the incidence of all DVTs, proximal DVT, and all PE including fatal PE has been reduced by low-dose UFH. ${ }^{75,76}$

LMWH has additional advantages over unfractionated heparin (Table 2). It can be given once or twice daily without laboratory monitoring. Other advantages are predictability, dose-dependent plasma levels, a long half-life, less bleeding for a given antithrombotic effect, and a lower incidence of heparin-induced thrombocytopenia than with UFH. ${ }^{77}$

The risk of heparin-induced osteoporosis is lower with LMWH than with UFH as it does not increase osteoclast number and activity. ${ }^{78}$ It has a far greater effect on inhibition of factor Xa and a lesser effect on antithrombin III by inhibiting thrombin to a lesser extent than UFH. ${ }^{79}$ Current contraindications to the early initiation of LMWH thromboprophylaxis include the presence of intracranial bleeding, ongoing and uncontrolled bleeding elsewhere, and incomplete spinal cord injury associated with suspected or proven spinal hematoma.

Fondaparinux, a synthetic pentasaccharide, has been approved for prophylaxis of DVT. It is an indirect selective inhibitor of factor Xa which binds to antithrombin with high affinity in a reversible manner. Heparin-induced thrombocytopenia has not been reported with fondaparinux as it does not interact with platelet function and aggregation, and has a predictable response. ${ }^{80}$ Monitoring of prothrombin time or partial thromboplastin time is also not required. In summary, it has an equal or better effectiveness than currently available agents, a low bleeding risk, no need for laboratory monitoring, and once daily administration.

Dabigatran is a new oral univalent direct thrombin inhibitor. Dabigatran etexilate is the prodrug of dabigatran. It is rapidly absorbed from the gastrointestinal tract with a bioavailability of $5 \%$ to $6 \%$. It has a half-life of 8 hours after single-dose administration and up to 17 hours after multiple doses with plasma levels that peak at 2 hours. ${ }^{81}$ The drug is excreted largely unchanged via the kidneys. It has a low bioavailability $(6 \%)$, produces a predictable anticoagulant effect, and requires no coagulation monitoring. ${ }^{81}$ Dabigatran has been approved in Canada and Europe for VTE prevention after orthopedic surgery.

The RE-COVER trial compared dabigatran etexilate with warfarin for 6 months in patients with acute VTE; dabigatran was as effective as warfarin in preventing recurrent VTE, with comparable major bleeding and significantly lower total bleeding rates. ${ }^{82,83}$ Another study (The RE-NOVATE II trial) compared the efficacy and safety of oral dabigatran with subcutaneous enoxaparin for extended thromboprophylaxis in patients undergoing total hip arthroplasty. ${ }^{82}$ Extended prophylaxis with oral dabigatran $220 \mathrm{mg}$ once daily was as effective as subcutaneous enoxaparin $40 \mathrm{mg}$ once daily in reducing the risk of VTE after total hip arthroplasty, and superior to enoxaparin for reducing the risk of major VTE. The risk of bleeding and safety profiles were similar. ${ }^{84}$

Rivaroxaban is a potent and selective oral factor Xa inhibitor. It has a rapid onset of action, a high bioavailability (80\%), and a half-life of 4 to 12 hours. ${ }^{81}$ EINSTIEN-DVT trial has shown that oral rivaroxaban is as effective in preventing recurrence of symptomatic VTE as the current standard therapy of injectable LMWH, enoxaparin, or fondaparinux, and an oral vitamin $\mathrm{K}$ antagonist in well-managed patients. ${ }^{85}$ The results of RECORD phase III trials have also shown that rivaroxaban $10 \mathrm{mg}$ once daily is superior to the LMWH enoxaparin, when used for prophylaxis of VTE in orthopedic surgeries. ${ }^{86}$ The drug also has the major advantages of once daily oral dosing and no required laboratory monitoring. Other drugs in this group such as apixaban and edoxaban are currently undergoing clinical trials.

Oral anticoagulation with vitamin $\mathrm{K}$ antagonists such as warfarin can be commenced preoperatively, at the time of surgery, or postoperatively for the prevention of VTE. ${ }^{87}$ Warfarin is contraindicated in antepartum thromboprophylaxis because it crosses the placenta and can result in unwanted teratogenicity and bleeding in the fetus. ${ }^{88}$ However the drug is safe during lactation as it does not accumulate in the breast milk to a substantial extent. ${ }^{89}$ Unlike warfarin, heparin is safe and it is recommended both in pregnancy and lactation. ${ }^{90}$

The use of aspirin alone is not recommended for thromboprophylaxis against VTE for any patient group. Some studies on the use of aspirin as prophylactic agent for DVT have shown some degree of protection against VTE in hospitalized patients, ${ }^{91,92}$ while other studies have either shown no benefit, ${ }^{93,94}$ or have proven to be less effective to other thromboprophylactic agents. ${ }^{95,96}$

The duration of thromboprophylaxis depends on the level of risk of VTE. For patients undergoing total hip replacement or hip fracture surgery, prolonged thromboprophylaxis beyond 10 days and up to 35 days is recommended especially for patients who are considered to be at high risk for VTE, while in patients admitted with acute medical illness thromboprophylaxis should be continued until discharge for the majority of the patients. ${ }^{87}$

\section{Treatment}

The goal of therapy for DVT is to prevent the extension of thrombus, acute PE, recurrence of thrombosis, and the 
development of late complications such as pulmonary hypertension and post-thrombotic syndromes. The initial treatment usually involves achieving a therapeutic dose of UFH or LMWH, or with fondaparinux.

Studies have shown that the efficacy of treatment with heparin largely depends on the ability to achieve a critical therapeutic ratio within the first 24 hours of treatment,, ${ }^{97,98}$ ie, achieving an activated partial thromboplastin time (aPTT) that is 1.5 times the mean of control value or the upper limit of normal aPTT range (aPTT ratio) of 1.5 to 2.5. This level corresponds to a heparin blood level of 0.3 to $0.7 \mathrm{U} / \mathrm{mL}$ by amidolytic antifactor Xa assay. ${ }^{99}$

Because of the advantages of LMWH, it is recommended over unfractionated UFH for treatment of acute DVT. UFH is, however, preferred in patients with severe renal failure as LMWH is mainly excreted via the kidneys. Heparin is initially given with warfarin and stopped after a minimum of 4 to 5 days, at which time the international normalized ratio (INR) should be within 2.0 to 3.0 (therapeutic range). This overlap with warfarin is essential because factors II, IX, $\mathrm{X}$ will not be affected until after 5 days, hence the intrinsic clotting pathway is intact. The initial prolongation of INR is mainly due to the effect of depression of factor VII which has a half-life of 5 to 7 hours.

Warfarin remains the drug of choice for long-term therapy to prevent clot formation once acute anticoagulation is achieved. LMWH is, however, preferred after longterm therapy of DVT in pregnancy as warfarin therapy is contraindicated, ${ }^{100}$ and in patients with cancer. Long-term anticoagulant therapy with LMWH is more effective than warfarin at preventing recurrent venous thrombosis in cancer patients without a statistically significant bleeding risk. ${ }^{101}$

The duration of anticoagulation depends on whether the patient has a first episode of DVT, ongoing risk factors for VTE disease, and known thrombophlebitis. ${ }^{102}$ In patients with first proximal DVT occurring in the context of a transient risk factor such as surgery or trauma, the risk of recurrence is very low and a limited duration of treatment (3 months) is adequate. ${ }^{103,104}$ Long-term anticoagulation therapy should be considered for recurrent thromboses, patients with ongoing risk such as active cancer and a first unprovoked proximal DVT or PE where no risk factors for bleeding are present, and where anticoagulation control is good. This may be particularly the case if D-dimer is raised after discontinuing anticoagulation, in males, in those with post-thrombotic syndrome, and in those with antiphospholipid antibodies. ${ }^{43,105}$

\section{Thrombolytic therapy}

This is rarely indicated. The risk of major bleeding, including intracranial hemorrhage, should be weighed against the benefits of a complete and rapid lysis of thrombi. It is indicated in massive DVT which leads to phlegmasia cerulean dolens and threatened limb loss. The available thrombolytic agents include tissue plasminogen activator, streptokinase, and urokinase.

Endovascular thrombolytic methods have evolved considerably in recent years. Catheter-directed thrombolysis (CDT) can be used to treat DVTs as an adjunct to medical therapy. ${ }^{106}$ Current evidence suggests that CDT can reduce clot burden and DVT recurrence and consequently prevent the formation of post-thrombotic syndrome compared with systemic anticoagulation. ${ }^{106}$ Pharmacomechanical CDT is now routinely used in some centers for the treatment of acute iliofemoral DVT. ${ }^{107}$

Appropriate indications may include younger individuals with acute proximal thromboses, a long life expectancy, and relatively few comorbidities. Limb-threatening thromboses may also be treated with CDT, although the subsequent mortality remains high. ${ }^{106} \mathrm{~A}$ number of randomized controlled trials are currently underway comparing the longer-term outcomes of CDT compared with anticoagulation alone.

\section{Vena cava filters}

Vena cava filters are indicated in very few circumstances. They include absolute contraindication to anticoagulation, life-threatening hemorrhage on anticoagulation, and failure of adequate anticoagulation. ${ }^{108}$ Absolute contraindications to anticoagulation include central nervous system (CNS) hemorrhage, overt gastrointestinal bleeding, retroperitoneal hemorrhage, massive hemoptysis, cerebral metastases, massive cerebrovascular accident, CNS trauma, and significant thrombocytopenia $(<50,000 /$ $\mu \mathrm{L}) .{ }^{108}$ They may be retrievable or nonretrievable, most of the newly developed ones being retrievable.

Studies to assess the effectiveness of filters revealed significantly fewer patients suffering PE in the short term, but no significant effect on PE. There was a higher rate of recurrent DVT in the long term. ${ }^{109}$ Complications of inferior vena cava filters include hematoma over the insertion site, DVT at the site of insertion, filter migration, filter erosion through the inferior vena cava wall, filter embolization, and inferior vena cava thrombosis/obstruction. ${ }^{110}$

\section{Conclusion}

DVT is a potentially dangerous clinical condition that can lead to preventable morbidity and mortality. A diagnostic pathway involving pretest probability, D-dimer assay, and venous 
ultrasound serves as a more reliable way of diagnosing DVT. Prevention consists of both mechanical and pharmacological modalities and is encouraged in both inpatients and outpatients who are at risk of this condition. The goal of therapy for DVT is to prevent the extension of thrombus, acute $\mathrm{PE}$, recurrence of thrombosis, and the development of late complication such as pulmonary hypertension and post-thrombotic syndrome.

\section{Disclosure}

The authors report no conflicts of interest and did not request or receive any form of financial support for this project.

\section{References}

1. Hirsh J, Hoak J. Management of deep vein thrombosis and pulmonary embolism. A statement for healthcare professionals. Council on Thrombosis (in consultation with the Council on Cardiovascular Radiology), American Heart Association. Circulation. 1996;93(12):2212-2245.

2. Silverstein MD, Heit JA, Mohr DN, et al. Trends in the incidence of deep vein thrombosis and pulmonary embolism: a 25 -year populationbased study. Arch Intern Med. 1998;158(6):585-593.

3. Naess IA, Christiansen SC, Romundstad P, Cannegieter SC, Rosendaal FR, Hammerstrøm J. Incidence and mortality of venous thrombosis: a population-based study. J Thromb Haemost. 2007;5(4):692-699.

4. Kyrle PA, Minar E, Bialonczyk C, Hirschl M, Weltermann A, Eichinger S. The risk of recurrent venous thromboembolism in men and women. $N$ Engl J Med. 2004;350(25):2558-2563.

5. Keenan CR, White RH. The effects of race/ethnicity and sex on the risk of venous thromboembolism. Curr Opin Pulm Med. 2007;13(5): 377-383.

6. Andrew M, David M, Adams M, et al. Venous thromboembolic complications (VTE) in children: first analyses of the Canadian Registry of VTE. Blood. 1994;83(5):1251-1257.

7. Van Ommen CH, Heijboer H, Buller HR, Hirasing RA, Heijmans HS, Peters M. Venous thromboembolism in childhood: a prospective twoyear registry in the Netherlands. J Pediatr. 2001;139(5):676-681.

8. Parasuraman S, Goldhaber SZ. Venous thromboembolism in children. Circulation. 2006;113:e12-e16.

9. Stein PD, Kayali F, Olson RE. Incidence of venous thromboembolism in infants and children: data from the National Hospital Discharge Survey. J Pediatr. 2004;145(4):563-565.

10. Bates SM, Ginsberg JS. Pregnancy and deep vein thrombosis. Semin Vasc Med. 2001;1(1):97-104.

11. Gader AA, Haggaz A, Adam I. Epidemiology of deep venous thrombosis during pregnancy and puerperium in Sudanese women. Vasc Health Risk Manag. 2009;5(1):85-87.

12. Simpson EL, Lawrenson RA, Nightingale AL, Farmer RD. Venous thromboembolism in pregnancy and the puerperium: incidence and additional risk factors from a London perinatal database. BJOG. 2001;108(1):56-60.

13. Hirsh J, Guyatt G, Albers GW, Harrington R, Schunemann HJ; the American College of Chest Physicians. Antithrombotic and thrombolytic therapy: American College of Chest Physicians evidencebased clinical practice guidelines, 8th ed. Chest. 2008;133(6 Suppl): $110 \mathrm{~S}-112 \mathrm{~S}$.

14. Geerts WH, Heit JA, Clagett GP, et al. Prevention of venous thromboembolism. Chest. 2001;119(1 Suppl):132S-175S.

15. Sandler DA, Martin JF. Autopsy proven pulmonary embolism in hospital patients: are we detecting enough deep vein thrombosis? $J R$ Soc Med. 1989;82(4):203-205.

16. Nicolaides AN, Kakkar VV, Field ES, Renney JT. The origin of deep vein thrombosis: a venographic study. $B r J$ Radiol. 1971;44(525): 653-663.
17. Brooks EG, Trotman W, Wadsworth MP, et al. Valves of the deep venous system: an overlooked risk factor. Blood. 2009;114(6):1276-1279.

18. Mitchell RN. Hemodynamic disorders, thromboembolic disease and shock. In Kumar V, Abbas AK, Fausto N. Robbins and Cotran Pathologic Basis of Disease. 7th ed. India: Elsevier; 2009:133.

19. Kearon C. Natural history of venous thromboembolism. Circulation. 2003;107(23 Suppl 1):122-130.

20. Kahn SR, Solymoss S. Lamping DL, Abenhaim L. Long-term outcomes after deep vein thrombosis: postphlebitic syndrome and quality of life. J Gen Intern Med. 2000;15(6):425-429.

21. Oudega R, Moons KGM, Hoes AW. Limited value of patient history and physical examination in diagnosing deep vein thrombosis in primary care. Family Practice. 2005;22(1):86-91.

22. Tapson VF, Carroll BA, Davidson BL, et al. The Diagnostic Approach to Acute Venous Thromboembolism. Clinical Practice Guideline. American Thoracic Society. Am J Respir Crit Care Med. 1999;160(3): 1043-1066.

23. Kahn SR. The clinical diagnosis of deep vein thrombosis: integrating incidence, risk factors and symptoms and signs. Arch Intern Med. 1998; 158(21):2315-2323.

24. Ikard RW, Ueland K, Folse R. Lower limb venous dynamics in pregnant women. Surg Gynecol Obstet. 1971;132(3):483-488.

25. Anderson FA, Wheeler HB. Physicians practices in the management of venous thromboembolism: a communitywide survey. J Vasc Surg. 1992;16(5):707-714.

26. Rosendaal FR. Risk factors for venous thrombosis: prevalence, risk, and interaction. Semin Hematol. 1997;34(3):171-187.

27. Prandoni P. Acquired risk factors for venous thromboembolism in medical patients. Pathophysiol Haemost Thromb. 2006;35(1-2):128-132.

28. Vandenbroucke JP, Rosing J, Bloemenkamp KW, et al. Oral contraceptives and the risk of venous thrombosis. N Engl J Med. 2001;344: 1527-1535.

29. Anderson FA, Spencer FA. Risk factors for venous thromboembolism. Circulation. 2003;107(Suppl 1):9-16.

30. Gavish I, Brenner B. Air travel and the risk of thromboembolism. Intern Emerg Med. 2010 Nov 6. [Epub ahead of print].

31. van Aken BE, Reitsma PH, Rosendaal FR. Interleukin 8 and venous thrombosis: evidence for a role of inflammation in thrombosis. $\mathrm{Br} \mathrm{J}$ Haematol. 2002;116:173-177.

32. Clayton TC, Gaskin M, Meade TW. Recent respiratory infection and risk of venous thromboembolism: case-control study through a general practice database. Int J Epidemiol. 2011. [Epub ahead of print].

33. Gertziafas GT. Risk factors for venous embolism in children. Int Angiol. 2004;23(3):195-205.

34. Rosendaal FR, Reitsma PH. Genetics of venous thrombosis. J Thromb Haemost. 2009;7 Suppl 1:301-304.

35. Oudega R, Hoes AW, Moons KG. The Wells rule does not adequately rule out deep venous thrombosis in primary care patients. Ann Intern Med. 2005;143(2):100-107.

36. Wells PS, Hirsh J, Anderson DR, et al. Accuracy of clinical assessment of deep-vein thrombosis. Lancet. 1995;345(8961):1326-1330.

37. Wells PS, Anderson DR, Bormanis J, et al. Value of assessment of pretest probability of deep-vein thrombosis in clinical management. Lancet. 1997;350(9094):1795-1798.

38. Pabinger I, Ay C. Biomarkers and venous thromboembolism. Arterioscler Thromb Vasc Biol. 2009;29:332-336.

39. Wells PS, Anderson DR, Rodger M, et al. Evaluation of D-dimer in the diagnosis of suspected deep-vein thrombosis. NEngl J Med. 2003;349: 1227-1235.

40. Aguilar C, del Villar V. Combined D-dimer and clinical probability are useful for exclusion of recurrent deep venous thrombosis. Am J Hematol. 2007;82(1):41-44.

41. Brotman DJ, Segal JB, Jani JT, Petty BG, Kickler TS. Limitations of D-dimer testing in unselected inpatients with suspected venous thromboembolism. Am J Med. 2003;114(4):276-282.

42. Eichinger S. D-dimer testing in pregnancy. Pathophysiol Haemost Thromb. 2003;33:327-329. 
43. Curry N, Keeling D. Venous thromboembolism: the role of the clinician. $J R$ Coll Phys Edinb. 2009;39:243-246.

44. Antonelli F, Villani L, Masotti L, Landini G. Ruling out the diagnosis of venous thromboembolism in the elderly: is it time to revise the role of D-dimer? Am J Emerg Med. 2007;25(6):727-728.

45. Masotti L, Ray P, Righini M, et al. Pulmonary embolism in the elderly: A review on clinical, instrumental and laboratory presentation. Vasc Health Risk Manag. 2008;4(3):629-636.

46. Nolan TE, Smith RP, Devoe LD. Maternal plasma D-dimer levels in normal and complicated pregnancies. Obstet Gynecol. 1993;81(2): 235-238.

47. Proietti AB, Johnson MJ, Proietti FA, Repke JT, Bell WR. Assessment of fibrin(ogen) degradation products in preeclampsia using immunoblot enzyme-linked immunosorbent assay and latex-based agglutination. Obstet Gynecol. 1991;77(5):696-700.

48. Francalanci I, Comeglio P, Liotta AA, et al. D-dimer concentrations during normal pregnancy, as measured by ELISA. Thromb Res. 1995; 78(5):399-405.

49. Goldenberg NA, Knapp-Clevenger R, Manco-Johnson MJ. Elevated plasma factor VIII and D-dimer levels as predictors of poor outcomes of thrombosis in children. N Engl J Med. 2004;351(11):1081-1088.

50. Hirsh J, Lee AY. How we diagnose and treat deep vein thrombosis. Blood. 2002;99:3102-3110.

51. Tovey C, Wyatt S. Diagnosis, investigation, and management of deep vein thrombosis Clinical review. BMJ. 2003;326:1180-1184.

52. Zierler BK. Ultrasonography and diagnosis of venous thromboembolism. Circulation. 2004;109(12 Suppl 1):I9-I14.

53. Kearon C, Ginsberg JS, Hirsh J. The role of venous ultrasonography in the diagnosis of suspected deep venous thrombosis and pulmonary embolism. Ann Intern Med. 1998;129(12):1044-1049.

54. Rose SC, Zwiebel WJ, Nelson BD, et al. Symptomatic lower extremity deep venous thrombosis: accuracy, limitations, and role of color duplex flow imaging in diagnosis. Radiology. 1990;175(3):639-644.

55. Kearon C, Julian JA, Newman TE, Ginsberg JS. Noninvasive diagnosis of deep vein thrombosis. McMaster Diagnostic Imaging Practice Guidelines Initiative. Ann Intern Med. 1998;128(8):663-677.

56. Rabinov K, Paulin S. Roentgen diagnosis of venous thrombosis in the leg. Arch Surg. 1972;104(2):134-144.

57. Tapson VF, Carroll BA, Davidson BL, et al. The Diagnostic Approach to Acute Venous Thromboembolism Clinical Practice Guideline. American Thoracic Society. Am J Respir Crit Care Med. 1999;160(3): 1043-1066.

58. Ting AC, Cheng SW, Cheung GC, Wu LL, Hung KN, Fan YW. Perioperative deep vein thrombosis in Chinese patients undergoing craniotomy. Surg Neurol. 2002;58(3-4):274-279.

59. Katayama H, Yamaguchi K, Kozuka T, Takashima T, Seez P, Matsuura K. Adverse reactions to ionic and non-ionic contrast media. A report from the Japanese Committee on the Safety of Contrast Media. Radiology. 1990;175(3):621-628.

60. Albrechtsson U, Olsson CG. Thrombotic side-effects of lower-limb phlebography. Lancet. 1976;1:723-724.

61. Glew D, Cooper T, Mitchelmore AE, Parsons D, Goddard PR, Hartog M. Impedance plethysmography and thrombo-embolic disease. Br J Radiol. 1992;65(772):306-308.

62. Fraser DG, Moody AR, Morgan PS, Martel AL, Davidson I. Diagnosis of lower-limb deep venous thrombosis: a prospective blinded study of magnetic resonance direct thrombus imaging. Ann Intern Med. 2002; 136(2):89-98

63. Erdman WA, Jayson HT, Redman HC, Miller GL, Parkey RW, Peshock RW. Deep venous thrombosis of extremities: role of MR imaging in the diagnosis. Radiology. 1990;174(2):425-431.

64. Roberts VC, Sabri S, Beeley AH, Cotton LT. The effect of intermittently applied external pressure on the haemodynamics of the lower limb in man. Br J Surg. 1972;59(3):223-226.

65. Agu O, Hamilton G, Baker D. Graduated compression stockings in the prevention of venous thromboembolism. Br J Surg. 1999;86(8): 992-1004.
66. Amaragiri SV, Lees TA. Elastic compression stockings for the prevention of deep vein thrombosis. Cochrane Database Syst Rev. 2000;3: CD001484.

67. Hull RD, Delmore TJ, Hirsh J, et al. Effectiveness of intermittent pulsatile elastic stockings for the prevention of calf and thigh vein thrombosis in patients undergoing elective knee surgery. Thromb Res. 1979;16(1-2):37-45.

68. Kakkos SK, Caprini JA, Geroulakos G, Nicolaides AN, Stansby GP, Reddy DJ. Combined intermittent pneumatic leg compression and pharmacological prophylaxis for prevention of venous thromboembolism in high-risk patients. Cochrane Database Syst Rev. 2008;4:CD005258.

69. Francis CW. Prophylaxis for thromboembolism in hospitalized medical patients. N Engl J Med. 2007;356:1438-1444.

70. Comerota AJ, Chouhan V, Harada RN, et al. The fibrinolytic effects of intermittent pneumatic compression: mechanism of enhanced fibrinolysis. Ann Surg. 1997;226(3):306-314.

71. Browse NL, Jackson BT, Mayo ME, Negus D. The value of mechanical methods of preventing postoperative calf vein thrombosis. Br J Surg. 1974;61(3):219-223.

72. Hilleren-Listerud AE. Graduated compression stocking and intermittent pneumatic compression device length selection. Clin Nurse Spec. 2009;23(1):21-24.

73. Chin PL, Amin MS, Yang KY, Yeo SJ, Lo NN. Thromboembolic prophylaxis for total knee arthroplasty in Asian patients: a randomised controlled trial. J Orthop Surg. (Hong Kong). 2009;17(1):1-5.

74. Morris RJ, Woodcock JP. Intermittent pneumatic compression or graduated compression stockings for deep vein thrombosis prophylaxis? A systematic review of direct clinical comparisons. Ann Surg. 2010; 251(3):393-396.

75. Collins R, Scrimgeour A, Yusuf S, Peto R. Reduction in fatal pulmonary embolism and venous thrombosis by perioperative administration of subcutaneous heparin. N Engl J Med. 1988;318(18):1162-1173.

76. Leonardi MJ, McGory ML, Ko CY. The rate of bleeding complications after pharmacologic deep venous thrombosis prophylaxis: a systematic review of 33 randomized controlled trials. Arch Surg. 2006;141(8): 790-797.

77. Warkentin TE, Levine MN, Hirsch J, et al. Heparin-induced thrombocytopenia in patients treated with low-molecular-weight heparin or unfractionated heparin. N Engl J Med. 1995;332(20):1330-1335.

78. Bhandari M, Hirsh J, Weitz JI, Young E, Venner TJ, Shaughnessy SG. The effects of standard and low molecular weight heparin on bone nodule formation in vitro. Thromb Haemost. 1998;80(3):413-417.

79. Hirsch J, Raschke R, Warkentin TE, Dalen JE, Deykin D, Poller L. Heparin: mechanism of action, pharmacokinetics, dosing considerations, monitoring, efficacy and safety. Chest. 1995;108(4 Suppl):258-275.

80. Bauer KA. Fondaparinux sodium: a selective inhibitor of factor Xa. Am J Health Syst Pharm. 2001;58 Suppl 2:S14-S17.

81. Weitz JI, Hirsh J, Samama MM. New Antithrombotic Drugs: American College of Chest Physicians Evidence-Based Clinical Practice Guidelines, 8th ed. Chest. 2008;133:234S-256S.

82. Schulman S, Kearon C, Kakkar AK, et al; RE-COVER Study Group. Dabigatran versus warfarin in the treatment of acute venous thromboembolism. N Engl J Med. 2009;361(24):2342-2352.

83. Dahl OE, Huisman MV. Dabigatran etexilate: advances in anticoagulation therapy. Expert Rev Cardiovasc Ther. 2010;8(6):771-774.

84. Eriksson BI, Dahl OE, Huo MH, et al; the RE-NOVATE II Study Group. Oral dabigatran versus enoxaparin for thromboprophylaxis after primary total hip arthroplasty (RE-NOVATE II). A randomised, double-blind, noninferiority trial. Thromb Haemost. 2011;105(4). [Epub ahead of print].

85. Effective single-drug approach is welcomed for deep-vein thrombosis treatment. Cardiovasc J Afr. 2010;21(5):301.

86. Chen T, Lam S. Rivaroxaban: an oral direct factor Xa inhibitor for the prevention of thromboembolism. Cardiol Rev. 2009;17(4):192-197.

87. Geerts WH, Bergqvist D, Pineo GF, et al. Prevention of venous thromboembolism: American College of Chest Physicians EvidenceBased Clinical Practice Guidelines 8th ed. Chest. 2008;133(6 Suppl): $381 \mathrm{~S}-453 \mathrm{~S}$ 
88. Hall JG, Pauli RM, Wilson KM. Maternal and fetal sequelae of anticoagulants during pregnancy. Am J Med. 1980;68:122-140.

89. Bates SM, Ginsberg JS. How we manage venous thromboembolism during pregnancy. Blood. 2002;100(10):3470-3478.

90. Ginsberg JS, Greer I, Hirsh J. Use of antithrombotic agents during pregnancy. Chest. 2001;119(1 Suppl):122S-131S.

91. Antiplatelet Trialists' Collaboration. Collaborative overview of randomised trials of antiplatelet therapy: III. Reduction in venous thrombosis and pulmonary embolism by antiplatelet prophylaxis among surgical and medical patients. BMJ. 1994;308(6923):235-246.

92. Hovens MM, Snoep JD, Tamsma JT, Huisman MV. Aspirin in the prevention and treatment of venous thromboembolism. J Thromb Haemost. 2006;4(7):1470-1475.

93. McKenna R, Galante J, Bachmann F, Wallace DL, Kaushal PS, Meredith P. Prevention of venous thromboembolism after total knee replacement by high-dose aspirin or intermittent calf and thigh compression. Br Med J. 1980;280(6213):514-517.

94. Powers PJ, Gent M, Jay RM, et al. A randomized trial of less intense postoperative warfarin or aspirin therapy in the prevention of venous thromboembolism after surgery for fractured hip. Arch Intern Med. 1989;149(4):771-774.

95. Graor RA, Stewart JH, Lotke PA, Davidson BL. RD heparin (ardeparin sodium) vs aspirin to prevent deep venous thrombosis after hip or knee replacement surgery [abstract]. Chest. 1992;102:118S.

96. Gent M, Hirsh J, Ginsberg JS, et al. Low-molecular-weight heparinoid orgaran is more effective than aspirin in the prevention of venous thromboembolism after surgery for hip fracture. Circulation. 1996;93(1):80-84.

97. Basu D, Gallus A, Hirsh J, Cade J. A prospective study of the value of monitoring heparin treatment with the activated partial thromboplastin time. N Engl J Med. 1972;287(7):324-327.

98. Hull RD, Raskob GE, Brant RF, Pineo GF, Valentine KA. Relation between the time to achieve the lower limit of the APTT therapeutic range and recurrent venous thromboembolism during heparin treatment for deep venous thrombosis. Arch Intern Med. 1997;157(22): $2562-2568$.

99. Hirsh J, Raschke R. Heparin and low-molecular-weight heparin the Seventh ACCP Conference on Antithrombotic and Thrombolytic Therapy. Chest. 2004;126(3 Suppl):188S-203S.
100. Hyers TM, Agnelli G, Hull RD, et al. Antithrombotic therapy for venous thromboembolic disease. Chest. 2001;119(1 Suppl): 176S-193S.

101. Lee AY, Levine MN, Baker RI, et al. Low-molecular-weight heparin versus a coumarin for the prevention of recurrent venous thromboembolism in patients with cancer. N Engl J Med. 2003;349(2):146-153.

102. Ramzi DW, Leeper KV. DVT and pulmonary embolism: Part II. Treatment and prevention. Am Fam Physician. 2004;69:2841-2848.

103. Levine MN, Hirsh J, Gent M, et al. Optimal duration of oral anticoagulation therapy: a randomized trial comparing four weeks with three months of Warfarin in patients with proximal deep vein thrombosis. Thromb Haemost. 1995;74(2):606-611.

104. Schulman S, Rhedin AS, Lindmarker P, et al. A comparison of six weeks with six months of oral anticoagulant therapy after a first episode of venous thromboembolism: Duration of Anticoagulation Trial Study Group. N Engl J Med. 1995;332(25):1661-1665.

105. Kearon C, Kahn SR, Agnelli G, et al. Antithrombotic therapy for venous thromboembolic disease: American College of Chest Physicians Evidence-Based Clinical Practice Guidelines, 8th ed. Chest. 2008;133(Suppl 6):454S-545S.

106. Patterson BO, Hinchliffe R, Loftus IM, Thompson MM, Holt PJ. Indications for catheter-directed thrombolysis in the management of acute proximal deep venous thrombosis. Arterioscler Thromb Vasc Biol. 2010;30(4):669-674.

107. Popuri RK, Vedantham S. The role of thrombolysis in the clinical management of deep vein thrombosis. Arterioscler Thromb Vasc Biol. 2011;31(3):479-484.

108. Streiff MB. Vena caval filters: a comprehensive review. Blood. 2000;95(12):3669-3677.

109. Decousus H, Leizorovicz A, Parent F, et al. A clinical trial of vena caval filters in the prevention of pulmonary embolism in patients with proximal deep-vein thrombosis. Prévention du Risque d'Embolie Pulmonaire par Interruption Cave Study Group. N Engl J Med. 1998; 338(7):409-415.

110. Joels CS, Sing RF, Heniford BT. Complications of inferior vena cava filters. Am Surg. 2003;69(8):654-659.
Journal of Blood Medicine

\section{Publish your work in this journal}

The Journal of Blood Medicine is an international, peer-reviewed, open access, online journal publishing laboratory, experimental and clinical aspects of all topics pertaining to blood based medicine including but not limited to: Transfusion Medicine; Blood collection, Donor issues, Transmittable diseases, and Blood banking logistics; Immunohematology; Artificial and alternative

\section{Dovepress}

blood based therapeutics; Hematology; Biotechnology/nanotechnology of blood related medicine; Legal aspects of blood medicine; Historical perspectives. The manuscript management system is completely online and includes a very quick and fair peer-review system. Visit http://www.dovepress.com/ testimonials.php to read real quotes from published authors. 